\title{
Accidental achievers? International higher education, class reproduction and privilege in the experiences of UK students overseas
}

\author{
Johanna Waters and Rachel Brooks
}

British Journal of Sociology of Education (published in 2010)

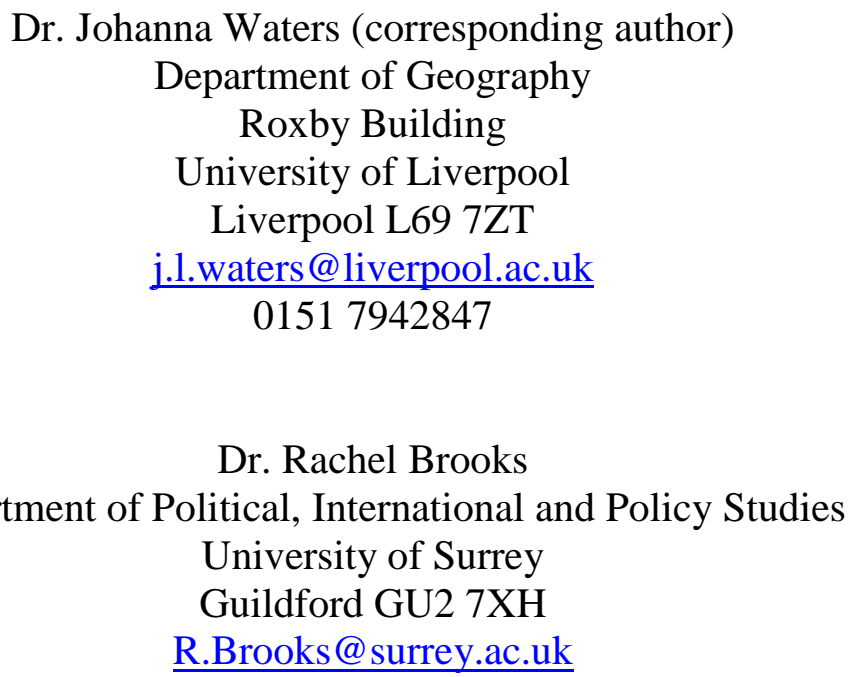

Word count: 6,616

Johanna Waters is a lecturer in Geography at the University of Liverpool, with degrees from the universities of Oxford and British Columbia. She has published widely on issues relating to transnational migration, family strategies and education.

Rachel Brooks is a Reader in Social Policy at the University of Surrey. Her interests include young people and higher education, lifelong learning and citizenship. She is author of numerous books and articles on these topics.

\section{$\underline{\text { Acknowledgements }}$}

We would like to thank the British Council for funding this research and Helena PimlottWilson for all her help with the data collection. Two referees provided helpful comments on a draft of this paper. We are also very grateful to all those that gave generously of their time to participate in this project. 


\begin{abstract}
To date, scholarship on international students has generally focussed on flows from nonWestern economies to the main English-speaking destination countries (such as the US, UK and Australia). In contrast, we draw on a qualitative study of 85 UK students, who have either completed or are considering undertaking a degree programme overseas. We found that, in opposition to a common image of 'international students', UK students are not overtly motivated by 'strategic' concerns. Instead, they are seeking 'excitement' and 'adventure' from overseas study and often use the opportunity to delay the onset of a career and prolong a relatively carefree student lifestyle. Despite these ostensibly 'disinterested' objectives, however, UK students remain a highly privileged group and their experiences serve only to facilitate the reproduction of their privilege. The paper calls for a more critical analysis of the spatially uneven and socially exclusive nature of international higher education.
\end{abstract}

\title{
Key Words
}

International higher education; UK students; strategies; mobility; migration; class 


\section{Accidental achievers? International higher education, class reproduction and privilege in the experiences of UK students overseas}

'I didn't make any effort, I didn't try, I didn't study, I could not be bothered [...] I grew up in a very spoilt environment, so of course, why did I have to do anything, you know? The world was going to come to me.'

- Richard, interviewee, completed higher education in Canada

\section{Introduction}

A great deal of work to date on the sociology of education has discussed the concept of 'strategy' in relation to middle-class decision-making around schooling, university and employment (e.g. Collins 1979; Bourdieu 1984; Brown 1995; Ball et al. 1995; Brown et al. 2003; Ball 2003). The general tenor of many of these arguments is that, with the 'democratisation' of access to formal education, the social advantage of middle-class families has come under threat. They have, consequently, had to find new ways of excluding workingclass participants from the most valued and sought-after occupations. Middle-class families can thus be seen, in the words of Brown et al. (1997), to employ 'exclusionary tactics [...] at a time of profound personal and social uncertainty' (14-15), to ensure their social reproduction and to maintain their position in the class structure (Bourdieu 1984). Most frequently, these tactics are portrayed as rational and calculating and undertaken with a fairly clear and explicit understanding of consequences (in terms of the economic and social rewards they will elicit). In national and local educational markets, such strategies might include the use of school league tables, moving house to be within a desired school 'catchment area', paying for a 
private education, stressing the importance of extra-curricular activities or employing personal tutors to enhance children's achievement. Within higher education, the choice of particular institutions or pursuit of Masters and Doctoral level qualifications are used to secure one's 'positional advantage' in relation to increasing numbers of others with commensurate undergraduate credentials (Brown and Hesketh 2004).

Such strategies are apparent, although rarely discussed, at an international scale (Waters 2006). As the relatively small academic literature on international and immigrant students would suggest, these individuals are equally engaged in the strategic and conscious pursuit of 'advantage' (Ong 1999; Balaz and Williams 2004; Waters 2006; Baas 2006; Collins 2006). Buoyed by their families, students are deeply concerned with acquiring the 'right' credentials and other embodied traits, which will be ultimately converted into social status and economic capital. Other, media and policy accounts point to high levels of strategy amongst international students when it comes to the choice of destination country, institution and subject of study (Shepherd 2008). Subject choices, for example, are usually closely aligned to specific career and ‘employability’ objectives: Institute of International Education data for the US show 41 percent of international students in 2006/2007 taking business and management, engineering, or mathematics and computer science (Open Doors 2007). Similarly, British Council data for the UK claim that 44 percent of international students are enrolled on business studies, engineering and technology, or physical and mathematical sciences programmes (compared to 9 percent for social science subjects) whereas in Australia, 65 percent take management/commerce, IT or engineering (British Council 2004). The demand for business studies is growing fastest and is predicted to increase from 14,000 in 2003 to 74, 000 in 2020 (British Council 2004). ${ }^{\mathrm{i}}$ International students, it would therefore seem, are very aware of the close relationship between credentials and employment 
outcomes, and the need to secure 'positional advantage' in an increasingly global knowledgebased economy (Brown and Hesketh 2004).

This paper makes an explicit attempt to bring together work in sociology of education around middle-class strategies and an increasingly vibrant research agenda examining the mobilities of international students. Despite this growing agenda, very little is still known about those emanating from English-speaking Western countries. A small number of academic studies on UK students have examined international movement (for 6-12 months) within a UK-based degree (as part, for example, of the Erasmus and Socrates programmes) (King and Ruiz-Gelices 2003; Findlay et al. 2006). However, there remains a significant gap in our knowledge of the motivations and experiences of UK students that choose overseas study for the whole of an undergraduate or postgraduate degree. The case of British students is particularly interesting, leaving the UK - one of the primary student destination countries for study abroad. Based on in-depth interviews, our research has sought to shed light on this hitherto unexplored aspect of international mobility, focussing on UK students seeking overseas education for the whole of an undergraduate or postgraduate degree, in a range of destination countries, as well as their subsequent employment experiences.

Attempts to explain international student migration stress, in different ways, the importance of accumulating 'capital' (Balaz and Williams 2004; Findlay et al. 2006; Waters 2006, 2008). International credentials are the embodiment of both 'human capital' and 'cultural capital', which can subsequently be exchanged for economic capital in the labour market (Bourdieu 1986). One of the most common and widely recognised advantages of an 'overseas' education for many students is the guarantee that it provides of proficiency in a foreign language, notably English (Balaz and Williams 2004, Waters 2006). However, this is unlikely to matter for international students emanating from English-speaking countries such 
as the UK. Other debates in sociology and education suggest the salience, for UK students and graduates, of issues such as 'employability', credential inflation, overpopulated graduate labour markets, and the consequent need to seek 'positional advantage' (e.g. Arthur and Rousseau 1996; Brown and Hesketh 2004; Brown and Lauder 2006; Moreau and Leathwood 2006). None of these discussions, however, engage with debates around international education and the possibility that UK students, when faced with the apparent reality of credential inflation, could choose to go overseas for their education. As entry levels to higher education in the UK reach 40 percent, an 'international' education, we suggest, may offer British students something scarcer and therefore more valuable than the 'norm' (Bourdieu 1996; Waters 2009) - securing their 'positional advantage' in the competition for graduate jobs.

This paper focuses on the reasons why $U K$ students (as opposed to international students more generally) decide to pursue an overseas education, in a climate where 'Education UK' is undoubtedly a desirable and highly sought after global brand (British Council 2004). It begins with a brief look at what we already know about international student mobility. We then introduce the specific case of UK students, suggesting the need to understand their decisions to study overseas in the context of recent debates within British and American sociology around credential inflation, graduate labour markets and employability. The project's methodology is discussed, before providing an in-depth look at the overseas mobility of UK students. We consider the claim that, in the (exceptional?) case of UK students, the 'cultural capital' associated with international education is not sought strategically but is accumulated 'accidentally', or without any conscious attempt to gain an explicit 'advantage' from overseas study. The paper uniquely and productively brings together different literatures and debates emanating from diverse disciplines to examine important emergent geographies of international higher education. 


\section{The international mobility of UK students}

To date, the internationalisation of education in the UK has been a rather one-sided process, involving the selling of 'Education UK' to overseas consumers (particularly through the work of the British Council) and the consequent 'importing' of thousands of students. The UK government's stance on international education was recently formalised through the 'Prime Minister's Initiative on International Education' (PMI) (1999 - 2004), and the PMI2, which was launched in April 2006. The PMI2 is a five year strategy (building on the first PMI) with the aim of securing the position of the UK as a 'leader in international education', with targets that include attracting an additional 70, 000 international students to the UK and significantly growing the number of partnerships between the UK and other countries, both by 2011. As already noted, along with the US and Australia, the UK is the foremost destination country for large numbers of international students, with over 270,000 in UK higher education (British Council 2004). Increasingly, higher education institutions in the UK are investing heavily in implementing 'internationalisation' strategies, as a number of recent policy reports (Fielden 2007) and dedicated practitioner conferences attest.

Very little attention has been paid however, in both policy and academic circles, to the implications for the UK of 'exporting' students, and, aside from piecemeal anecdotal evidence, knowledge of this is scant. The Times Higher Education recently included a small feature on UK students overseas, suggesting that 'unprecedented numbers of British teenagers are considering shunning UK universities for US colleges in the hope of a broader, cheaper and more luxurious education' (Shepherd 2008, no pagination). The Fulbright Commission, which funds UK students to study in the US, reported 700, 000 inquiries in 2007, which represents a three-fold increase on the previous year (Shepherd 2008). In another 
media account, concerns over 'cost' and the relatively high tuition fees (particularly at Masters and $\mathrm{PhD}$ levels) faced by students in the UK were given as a reason why increasing numbers would seem to be interested in studying abroad. Countries such as Sweden and the Netherlands offer postgraduate tuition in the English language for a fraction of the cost of an equivalent UK-based course (Clark 2006). There is a need, however, for a far more detailed analysis of UK students and their role in global international population flows.

Addressing this gap, the project on which this paper draws included in-depth interviews with 85 UK students and graduates conducted in 2007/2008. The sample comprised 40 sixthformers and undergraduates who were seriously considering study overseas, and 45 graduates who had completed either an undergraduate or postgraduate degree abroad. It was anticipated that choices may be configured differently for individuals studying at undergraduate and postgraduate level, and we therefore included approximately equal numbers of both in the sample. Participants were recruited through diverse channels, including state and private schools in the UK located in Surrey, Greater Manchester, Merseyside and Cumbria, the Fulbright Commission, the Canadian Rhodes Scholars Foundation, the Commonwealth Scholars Commission, 65 alumni associations, and advertisements placed on university notice pages. The spread of subject areas pursued by students was wide and included: geography, economics, psychology, politics, international relations, literature, Viking studies, zoology, mathematics, nuclear physics, engineering, journalism, shark behaviour and education. However, we recognise that our sampling method may not have captured the total population of UK students overseas, and there is an inevitable bias towards those particular schools and universities that provided us with the most help.

Our data indicate that there was much less geographical diversity in relation to undergraduate study than there was at postgraduate level: high status universities in the US 
(Ivy League) were by far the most common destinations amongst the former group. In contrast, for postgraduate study, many more respondents had considered or were considering institutions outside the US (although North America as a whole still dominated student choices). Notably, across the sample there were only four respondents who either had or were planning to study in a language other than English.

It is also important to note the socio-economic characteristics of our sample. Socioeconomic diversity was far more apparent for our 'postgraduates' (i.e. those thinking of studying for, or having completed, a postgraduate degree overseas) than it was at the 'undergraduate' level (i.e. amongst individuals that were thinking of/had completed an undergraduate degree abroad). Nineteen out of 31 of our 'undergraduate' respondents had attended a private school, compared to only 12 out of 54 'postgraduates'. The 'undergraduate' group had all followed a traditional path through school to university, with 'gap years' being the only break in study. In contrast, our 'postgraduate' sample also contained some individuals who had more 'unconventional' educational histories (e.g. mature students). Thus, whilst international education is usually associated with a privileged upbringing (and this aspect is highlighted in this paper), this is not always and necessarily the case. Nevertheless, taken as a whole, the characteristics of the respondents indicate that international students from the UK do represent a highly privileged group, with access to significant amounts of capital (social, cultural and economic). Interviews demonstrated privilege in a number of different ways, including the degree of parental support and involvement in education, familial expectations with regard to educational achievement and the amount of/quality of capital invested by the family (Coleman 1988). School, peer and familial pressure to attend a 'good' university was widely apparent, and evidence points to the salience of the concept of habitus (Bourdieu 1984) for capturing the totality of environmental and social influences (the multiple dimensions of privilege) coming together 
to make international education a viable, imaginable option for our participants. The biographies of students and graduates showed the importance of travel (as a child or young adult) - whether on family or school trips, as part of a 'gap year' or as a 'year abroad' within an undergraduate degree programme. Parents were almost always highly supportive, and would demonstrate this in material as well as less tangible ways, frequently offering to foot the bill for overseas study.

\section{Strategy or the accidental accumulation of capital?}

Given what we know already about both middle-class strategies around education and the apparent widespread strategising of international students, one of the most striking and unexpected findings to have emerged from our study was the ostensible absence of any explicit strategy underpinning many UK students' decisions around international education. The lack of conspicuous strategising was evident from the data in a number of ways. Most notable, perhaps, is what individuals did not say with regards to their decision-making; only a handful of participants made any reference at all to employment and the economic advantages that would eventually accrue to them from pursuing an international education. This observation contrasts starkly with extant understandings of international students, where employability considerations (and particularly the assumed perceptions of employers) are of utmost importance (Waters 2008; Shepherd 2008). When asked why they were thinking, or had originally thought of studying overseas, the vast majority of individuals stressed 'excitement', 'glamour' and 'adventure'. Jamie, an undergraduate considering going overseas for postgraduate study, captures this sense of the absence of strategy. He said: 
'I don't really see any of my education or academic studies or cultural enrichment or anything I partake in, in my life, as contributing to a final goal or career prospect; none whatsoever. It's purely to develop myself as a person so as to sort of have a more objective understanding of the world and be able to perhaps contribute in a more positive way. Whereas as - this sounds very much like something a hippy would say, but you know, like - as opposed to sort of trying to use my academic studies for sort of monetary gain in the future, so to speak.'

The lack of apparent strategy - particularly around career and monetary gain - was striking. Jamie's personal objectives when it comes to his educational decisions were not unique but, on the contrary, highly representative of the majority of views expressed by our research participants. Clearly, we need a different conception of 'strategy' in this instance - one not associated with highly rational and overtly calculating decision making, but one that makes choices appear disinterested, even when they may ultimately result in the (same) reproduction of class privilege. For Pierre Bourdieu (1984), who has theorised extensively on the relationship between class strategies, social reproduction and education, 'strategy' amongst the most privileged individuals (particular the upper-middle-classes) has very different connotations than it does for working- and lower-middle-class groups. He writes:

\footnotetext{
'To speak of strategies of reproduction is not to say that the strategies through which dominants manifest their tendency to maintain the status quo are the result of rational calculation or even strategic intent. It is merely to register that many practices that are phenomenally very different are objectively organised in such a way that they
} 
contribute to the reproduction of the capital at hand, without having been explicitly designed and instituted with this end in mind' (Bourdieu 1984, 272, emphasis added).

Bourdieu's theorisations - and particularly the concept of habitus - allow us to transcend the often-assumed dichotomy between rational and calculated action on the one hand and unconscious practices on the other. Consequently, educational strategies can be both conscious and unconscious, and should not therefore be always reduced to 'the economics of "human capital"' (Bourdieu 1984, 273) - in other words, to an overt concern with "profitable outcomes' from investment in education (as much of the recent writing on the 'exclusionary tactics' of middle-class families in relation to education might imply - see Ball 2003). For the most privileged members of society, the pursuit of education can be seen as part of a more general 'aesthetic disposition': a 'capacity to neutralize ordinary urgencies and to bracket off practical ends, a durable inclination and aptitude for practice without a practical function, [which] can only be constituted within an experience of the world freed from urgency and through the practice of activities which are an end in themselves' (Bourdieu 1984, 54). The ability to take such an 'un-instrumental' view of education depends, importantly, on an individual's 'past and present material conditions of existence' (Bourdieu 1984, 53/54) and the capacity to 'withdraw' from concerns over 'economic necessity'. Furthermore, this allows such privileged individuals the additional advantage of being seen (and of seeing themselves) 'as perfectly disinterested, unblemished by any cynical or mercenary use of culture' (Bourdieu 1984, 86).

This conception of 'strategy' has far more resonance with the motivations and objectives of our sample of UK students than does a more instrumental view of 'choice' around education (e.g. Collins 1979; Ball et al. 1995; Waters 2006, 2008). Richard, who graduated 
from a university in Canada, epitomises the 'accidental' accumulation of valuable cultural capital. He was able to reflect upon the level of privilege he had experienced growing up and was open about his pursuit of 'aesthetic' (as opposed to overtly career-oriented) goals:

'I left school with five GCSEs, two Bs and three Cs - very, very poor. I didn't make any effort, I didn't try, I didn't study, I could not be bothered. I had no...I was very lazy and unmotivated. I had no desire. I grew up in a very spoilt environment, so of course, why did I have to do anything, you know? The world was going to come to me.'

After leaving school, he worked for two years in a video store, and during that time discovered his love of American football: '[For] someone who is easily bored, the thought of suddenly studying in America would be, you know, wow, amazing.' He had imagined studying abroad would be 'just one big juicy adventure [...] the adventure of it just swept me away, a big grand adventure you know.' When asked how he had envisaged an overseas education fitting into his 'future plans', he replied:

'I don't think I had a future plan, to be honest. My future plan was to avoid working and sleep late! And that fitted in well because of course it meant a guaranteed four year pass out of employment. At the time that was a massive motivation. I just didn't want to work and I wanted to find any way possible to avoid doing anything I didn't want to do.' 
Richard spent six years in Canada completing an undergraduate degree, funded by his parents, and now works as head of marketing at a large beauty chain based in the UK. Even he would freely admit to having 'fallen on his feet', almost despite his best efforts. His claim that he had 'no plan' for his future, when decisions around overseas study were being made, was not uncommon. Another participant, Idris, was considering studying for a Masters in law somewhere in Europe. However, she claimed: 'I don't really have, like, any kind of great long-term career plan. I'd say I'm kind of, like, I want to do this and see, like, what avenues it opens up, and see where I go from there.' The vagueness of her plans undoubtedly reflect a confidence that she will similarly 'land on her feet' whatever her decision, perhaps born of her privileged experiences to date. When asked what advantages she had envisaged from studying abroad, Alice replied:

'I didn't think it would offer me anything other than the ability to go abroad [...]. I didn't have any idea what I wanted to do for a career. I don't think I was that really focussed on it really, I just wanted to have an experience of living abroad. So I think, all it was was an ability to get me abroad [...]. I think I thought I'd worked really hard, I worked hard at school, I worked hard at university, and I just thought I wanted some time having some fun.'

Numerous examples from our interviews demonstrate what Bourdieu (1984) described as 'an experience of the world freed from urgency' and 'the practice of activities which are an end in themselves' (54). Lillian went on to describe her overseas education as 'something I was doing purely for myself, for fun'; Shaun said: ‘to be perfectly honest, I wasn't very much 
thinking about advantage. I mean, I was quite interested in studying longer and I wanted to travel, and so it was an end in itself'; whereas Patrick said of his own aims: 'I didn't think about mortgages and things like that [...]. I didn't have any future plans - everything was a lark.'

Opportunities to study overseas sometimes came along inadvertently. Tracy admitted that her failure to 'work hard' as an undergraduate had meant that she was unable, consequently, to secure a place on her preferred UK-based Masters course. Then the option of studying in Canada 'appeared': 'I never really made the conscious decision to go, it had just been thrown at me, like - 'well why not try this?' [...] Initially I thought, well, this is probably the only way I'm going to get further in to do graduate work [...]. Now I look back I think there's a lot more advantages to, you know, having gone there.' Again, this example resonates strongly with Bourdieu's concept of habitus, wherein unconscious daily practices can lead inadvertently to social advantage for privileged individuals.

For some participants, far from representing a strategic long-term career move, overseas study offered an alternative to starting one's career - a way of forestalling the inevitable (i.e. the commitment associated with full-time employment). When asked what had prompted her thoughts about overseas study, Lillian replied: 'I didn’t want to get a proper job! [Interviewer: $O K]$ Didn't want to do the milk round ${ }^{\mathrm{ii}}$ and didn't....really wanted to live abroad. It wasn't the study, it was living abroad.' Reflecting on his decision to spend two years pursuing a Masters degree in Canada, Ralph said:

'Did I want to go straight to my career or did I want to buy some time really and go and study? And you know, in the end my decision was that it wouldn't hurt, you know, 
there will always be jobs out there, but you know there will only be this one, I could live to regret [missing] this opportunity to go and have someone pay me to study abroad, and go and live abroad, and go and have the luxury of being a student, you know, which is a luxury in many ways. To go and explore what you want to explore, research what you want to research, and someone is paying you to do it and paying you very nicely to do it [...]. My decision was, if I don't do it I'll regret it, and that was it really. And do you know, it was a hard decision because, as I say, the company I had a job offer with clearly wanted me and were very, you know, it was amazing money and it was an amazing deal.'

In this account, we see a decision being made between starting employment in a company with excellent monetary and other rewards and pursuing an 'adventure' abroad. Intriguingly, no association is drawn between the furthering of his education and improved employment prospects, challenging prevalent assumptions linking employability, individual responsibility and postgraduate learning (e.g. Bowman 2005). His sense that 'there will always be jobs out there' reflects a lack of urgency associated with privileged individuals able to 'withdraw' from concerns over 'economic necessity’ (Bourdieu 1984).

The pursuit of pleasure and 'experience for experience's sake' (evoking Bourdieu's (1984) 'aesthetic disposition') was widely evident in the reasons individuals gave for undertaking study abroad. Ceri, for example, was asked what she thought she would 'get out of overseas study': 
'Well, a different experience from a different country which, I mean you don't, if you travel to somewhere you usually see it and you see the sights, but you don't actually really get to know what a place is like unless you live there. [...] I feel going to study abroad I can get the knowledge I want from a PhD but get a lot of other experiences as well....and meet different people, different lifestyles, different cultures.'

Idris similarly said: 'I've always had, wanted to see different places and kind of seek out those experiences and try and get a greater understanding through seeing different places.' These extracts evoke Ulf Hannerz's (1996) notion of 'the cosmopolitan', forever searching for difference and yet, at the same time, always 'knowing where the exit is'. The spaces inhabited by the cosmopolitan are often 'bounded and elitist' and 'marked by a specialized and - paradoxically - rather homogenous transnational culture, a limited interest in engaging 'the Other', and a rather restricted corridor of physical movement between defined spaces' (Vertovec and Cohen 2002, 7). The tendency for students to pursue 'difference' in the US would seem to represent just that - a rather circumscribed engagement with 'the Other'. In fact, much of what students seemed to know about the US - and the excitement and adventure they associated with it - would seem to have come through exposure to films and television.

On the whole, undergraduate and postgraduate experiences of overseas study were almost uniformly positive, and articulated not in relation to any objective 'advantage' they bestowed, such as improved employment prospects, but in terms of a personally rewarding 'life experience'. Any 'career' advantages gained (and some were mentioned) were portrayed as incidental. The interviews, particularly those conducted with the most privileged individuals, display the 'playful seriousness' that Bourdieu (1984) invokes when he says: 'one has to 
belong to the ranks of those who have been able, not necessarily to make their whole existence a sort of children's game, but at least to maintain for a long time, sometimes a whole lifetime, a child's relation to the world.' (54)

Our findings correspond to those of Brooks and Everett (2008) in their work on the incidence of 'life planning' amongst graduates in the UK. They review several studies about young adults' propensity to plan and note the differences that emerged 'by social position' (326) - whereas privileged individuals would seem to design their lives in some detail, those from socially disadvantaged backgrounds would eschew such planning. In contrast, Brooks and Everett (2008) found a strong association between a privileged upbringing and a 'disinclination to form detailed plans for the future' (335). In explanation, they suggest that socially advantaged young adults 'felt little need to plan because of a secure and highly advantaged family background' - they may have sensed that the 'carefree' nature of their present circumstances would not last, and so they would enjoy it whilst they could (Brooks and Everett 2008, 331). Amongst our sample, enjoyment was a strong motivator for overseas study, wherein individuals were able to 'bracket off practical ends' and seek pleasure as a goal in itself (Bourdieu 1984, 54). And yet, even if we accept that UK students' decisions regarding study overseas are usually unstrategic and made with only the vaguest conscious notion of accruing 'profit', we nevertheless have to confront the fact that the choices they make will often result in the reproduction of middle-class privilege.

\section{Conclusion}

This paper has provided an exploration of UK students' experiences of overseas study. It has argued that, in an intense period of higher education 'internationalisation', very little is 
still yet known about the experiences and motivations of international students - particularly those from English speaking 'Western' countries. An examination of recent work on the sociology of education indicates the importance of the concept of 'strategy' in relation to middle-class decision-making around schooling and higher education. In a purportedly saturated graduate labour market, gaining 'positional advantage' through educational choice is as important as ever. Similarly, a separate but related body of work on international students suggests the salience of the accumulation of cultural capital (such as linguistic skills) in motivating their decision to study abroad. The focus of this work, however, has generally been on students moving from non-English speaking to English-speaking Western countries (or countries where the medium of educational instruction is English). To date, very little has been known about the motivations and objectives of students moving from English-speaking countries such as the UK. We have asked: how relevant is the concept of 'strategy' in this instance? The paper has drawn on a recent study of 85 UK students and graduates who have either completed or are seriously considering completing a degree course overseas. What we have found is that, contrary to expectations, these individuals displayed very little by way of 'strategic intent' when it came to decision-making around overseas study. In fact, any sense that an overseas education would confer some 'advantage' (over and above a home-based qualification) was noticeably absent. Instead, for many interviewees, international education seemed to represent an active shunning of 'life-planning' and the responsibilities associated with employment. Going overseas offered opportunities for 'excitement', 'glamour' and 'fun' and a way of deferring the inevitable encroachment of a 'career'. These findings go against what we know of international students more generally - that they are highly strategic and focussed primarily on subsequent careers, where their choice of institutions and subjects reflect explicit attempts to maximise their accumulation of 'cultural capital' (Bourdieu 1984), which can later be converted into economic capital in the labour market. In this paper, we 
have conceptualised our findings in terms of the 'accidental achievement' of UK students who, despite their claims of disinterestedness, nevertheless appear to be generally successful in everything they do.

The work of Bourdieu $(1984,1996)$ has been particularly helpful in allowing us to understand the apparent conflict between what we know of middle-class strategies around education (on which there is a substantial literature) and the findings uncovered in this research - an apparent tension between 'strategy' and the 'accidental' accumulation of capital. For the most privileged members of society, amongst which many of our research participants would count, practices of social reproduction are neither purely conscious nor unconscious, but are subsumed within a more general 'aesthetic disposition' within the habitus, wherein 'ordinary urgencies' and material concerns are put to one side and in their place can be found the tendency to pursue pleasure and experience for experience's sake.

And yet, the paper has also argued, the choices which these individuals have made with regards to their education may nevertheless result in the reproduction of their privilege. This becomes clear when we examine the destinations of UK students. They are focussed on 'world class' institutions abroad, and particularly Ivy League universities in the United States. The opportunities to study at these institutions presented themselves not by accident, but most usually in association with particular experiences of (private) schooling and parental involvement in education.

One of the main conclusions to be drawn from this work, then, is that despite the fact that increasing numbers of individuals, globally, have access to higher education, and that opportunities for international study appear to be growing, educational opportunities (and the extent of 'achievement' that results from these) continue to be differentiated by social class background. It supports widespread claims that real 'choice' in education is often a myth, as 
are any remaining associations between this and positive outcomes for social mobility. There is a pressing need to examine further the uneven and often exclusive geographies of international student mobility. 


\section{Bibliography}

Arthur, M. B. and D. M. Rousseau. 1996. Introduction: the boundaryless career as a new employment principle. In The Boundaryless Career: A New Employment Principle for a New Organizational Era, ed. M. B. Arthur and D. M. Rousseau, 3 - 20. New York: Oxford University Press.

Balaz, V. and A. Williams. 2004. 'Been there, done that': international student migration and human capital transfers from the UK to Slovakia. Population, Space and Place 10: 217 - 237.

Ball, S. 2007. Education plc: Understanding Private Sector Participation in Public Sector Education. Oxford: Routledge.

Ball, S. 2003. Class Strategies and the Education Market: The Middle Classes and Social Advantage. London: Routledge.

Ball, S., R. Bowe and S. Gewirtz. 1997. Circuits of Schooling: a sociological exploration of parental choice of school in social-class contexts. In Education: Culture, Economy, Society, ed. A. Halsey, H. Lauder, P. Brown and A. S. Wells, 409 - 421. Oxford: Oxford University Press.

Baas, M. 2006. Students of migration: Indian overseas students and the question of permanent residency. People and Place 14, $9-24$.

Bourdieu, P. 1984. Distinction; a Social Critique of the Judgement of Taste. Cambridge Massachusetts: Harvard University Press.

Bourdieu, P. 1996. The State Nobility: Elite Schools in the Field of Power. Stanford: Stanford University Press.

British Council. 2004. Vision 2020: Forecasting International Student Mobility. Report produced with Universities UK and IDP Education Australia.

Brown, P. 1995. Cultural capital and social exclusion: some observations on recent trends in education, employment, and the labour market. Work, Employment and Society 9: 29 - 51.

Brown, P., A. H. Halsey, H. Lauder and A. Stuart Wells. 1997. The transformation of education and society: an introduction. In Education: Culture, Economy, Society, ed. A. Halsey, H. Lauder, P. Brown and A. S. Wells, 1 - 44. Oxford: Oxford University Press.

Brown, P. and A. Hesketh. 2004. The Mismanagement of Talent: Employability and Jobs in the Knowledge Economy. Oxford: Oxford University Press.

Bowman, H. 2005. 'It's a year and then that's me': masters students' decision-making. Journal of Further and Higher Education 29: 233 - 249.

Brooks, R. and G. Everett. 2008. The prevalence of 'life-planning': evidence from UK graduates. British Journal of Sociology of Education 29: 325 - 337. 
Brown, P., A. Hesketh and S. Williams. 2003. Employability in a knowledge-driven economy. Journal of Education and Work 16: 107 - 126.

Brown, P. and H. Lauder. 2006. Globalisation, knowledge and the myth of the magnet economy. Globalisation, Societies and Education 4: 25 - 57.

Clark, T. 2006. A free lunch in Uppsala. The Guardian, 24 October, no pagination.

Coleman, J. 1988. Social capital in the creation of human capital. American Journal of Sociology 94: S95 - S120.

Collins, F. L. 2006. Making Asian students, making students Asian: the racialisation of export education in Auckland, New Zealand. Asia Pacific Viewpoint 47: 217 - 234.

Collins, R. 1979. The Credential Society: an Historical Sociology of Education and Stratification. New York: Academic Press.

Fielden, J. 2007. Global Horizons for UK Students: A Guide for Universities. The Council for Industry and Higher Education.

Findlay, A., R. King, A. Stam and E. Ruiz-Gelices. 2006. Ever reluctant Europeans: the changing geographies of UK students studying and working abroad. European Urban and Regional Studies 13: 291 - 318.

Granovetter, M. 1973. The strength of weak ties. American Journal of Sociology 78: 1360 1380 .

Hannerz, U. 1996. Transnational Connections: Culture, People, Places. London: Routledge

IIE. 2007. Current Trends in US Study Abroad and the Impact of Strategic Diversity Initiatives. The Study Abroad White Paper Series, Issue Number 1.

King, R. and E. Ruiz-Gelices. 2003. International student migration and the European 'yearabroad': effects on European identity and subsequent migration behaviour. International Journal of Population Geography 9: 229 - 252.

Li, L, A. Findlay, A. Jowett and R. Skeldon. 1996. Migrating to learn and learning to migrate. International Journal of Population Geography 2: 51 - 67.

Moreau, M. P. and C. Leathwood. 2006. Graduates' employment and the discourse of employability: a critical analysis. Journal of Education and Work 19: 305 - 324.

OECD. 2007. Education at a Glance. OECD Publications.

Ong, A. 1999. Flexible Citizenship: the cultural logics of transnationality. Durham, Duke University Press. 
Open Doors. 2007. Report on International Educational Exchange. http://opendoors.iienetwork.org, accessed 11/08/2008.

Rivza, B. and Teichler, U. 2007 'The changing role of student mobility' Higher Education Policy 20, $457-475$.

Shepherd, J. 2006. UK Students Drawn to US for Broad-Based Degrees, Times Higher Education, 4 August 2006.

Shepherd, J. 2008. 'Why I chose the university of wherever' Education Guardian Tuesday February 5: 14.

Vertovec, S. and R. Cohen. 2002. Introduction: conceiving cosmopolitanism. In Conceiving Cosmopolitanism: Theory, Context, and Practice, ed. S. Vertovec and R. Cohen, $1-24$. Oxford: Oxford University Press.

Waters, J. L. 2006. Geographies of cultural capital: education, international migration and family strategies between Hong Kong and Canada. Transactions of the Institute of British geographers 31: 179 - 192 .

Waters, J. L. 2008. Education, Migration and Cultural Capital in the Chinese Diaspora: transnational students between Hong Kong and Canada. New York: Cambria Press

Waters, J. L. 2009. In pursuit of scarcity: transnational students, 'employability', and the MBA. Environment and Planning A 41 (8): 1865 - 1883.

\footnotetext{
' Subject based demand has a very particular geography - Western Europe and North American accounted for 60 percent of total demand for arts/humanities subjects in 2003 whereas the growing demand for business studies is driven largely by students from East Asia.

ii The 'milk round' is an annual visit to universities in the UK, when recruiters from large commercial companies attempt to sign-up future employees.
} 